
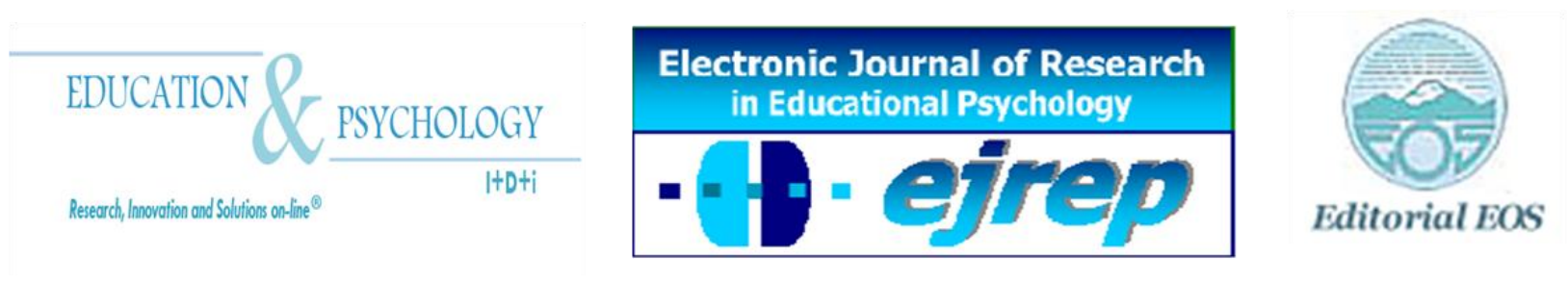

\title{
The Accuracy of Metacomprehension Judgments: The Biasing Effect of Text Order
}

\section{Tracy Linderholm ${ }^{1}$, Xuesong Wang ${ }^{2}$, David Therriault ${ }^{3}$, Qin Zhao ${ }^{4}$, \& Laura Jakiel ${ }^{5}$}

\author{
${ }^{1}$ Department of Curriculum, Foundations, \& Reading, \\ Georgia Southern University, Statesboro, Georgia \\ ${ }^{2}$ Department of Curriculum \& Instruction, \\ Texas A \& M International University, Laredo, Texas \\ ${ }^{3}$ School of Human Development \& Organizational Studies in Education, \\ University of Florida, Gainesville, Florida \\ ${ }^{4}$ Department of Psychology, Western Kentucky University, \\ Bowling Green, Kentucky \\ ${ }^{5}$ Department of Educational Psychology, Florida State University, \\ Tallahassee, Florida
}

USA

Correspondence: Tracy Linderholm, College of Education, Department of Curriculum, Foundations, \& Reading, Georgia Southern University, P.O. Box 8013, Statesboro, GA 30460 USA. E-mail: tlinderholm@georgiasouthern.edu

(C) Education \& Psychology I+D+i and Editorial EOS (Spain) 


\section{Abstract}

Introduction. Two experiments tested the hypothesis that relative metacomprehension accuracy is vulnerable when readers' cognitive efforts are biased by text order. It is proposed that the difficulty level of initial text information biases readers' estimates of text comprehension but is correctable when more cognitive effort is applied.

Method. In both experiments, participants were randomly assigned to read a series of expository texts in one of two text order conditions: easy-to-hard and hard-to-easy. Readers made estimates of their comprehension and took comprehension tests over their understanding of the texts in the series in order to determine relative metacomprehension accuracy.

Results. Experiment 1 revealed that reading texts ordered easy-to-hard resulted in lower average relative metacomprehension accuracy compared to texts ordered hard-to-easy. In Experiment 2, when participants were explicitly instructed to put more cognitive effort in to the task, the biasing effects of text order were eliminated.

Discussion and Conclusion. These results expand one tenet of the optimum-effort hypothesis that relative metacomprehension accuracy is minimized when reading is perceived to be easy, requiring little cognitive effort.

Keywords: Metacomprehension; Reading Comprehension; Relative Accuracy; Cognitive Effort Hypothesis. 


\section{La precisión de juicios metacomprensivos: el efecto sesgador del orden del texto Resumen}

Introducción. Dos experimentos probaron la hipótesis que propone que la exactitud relativa de la metacomprensión es vulnerable cuando los esfuerzos cognitivos del lector son influenciados por el orden del texto. Se propone que el nivel de dificultad inicial de la información del texto influye la apreciación de comprensión del texto pero es corregible al aplicar más esfuerzo cognitivo.

Método. En los dos experimentos, los participantes fueron asignados al azar, a la tarea de leer una serie de textos expositivos en una de dos condiciones: fácil a difícil y difícil a fácil. Los lectores hicieron estimaciones de su comprensión y realizaron exámenes de comprensión sobre su entendimiento de los textos, en la series, para determinar su exactitud relativa de metacomprensión.

Resultados. El experimento 1 reveló que leer textos en orden fácil a difícil resultó en niveles de exactitud relativa de metacomprensión más bajos, en comparación con textos en orden difícil a fácil. En el experimento 2, al dar a los participantes instrucciones explícitas de poner más esfuerzo cognitivo a la tarea, los efectos de la influencia del orden del texto fueron eliminados.

Discusión y Conclusión. Estos resultados expanden una doctrina de la teoría The OptimumEffort Hypothesis (Hipótesis del Esfuerzo Óptimo) que establece que la exactitud relativa de metacomprensión es minimizada cuando la lectura se percibe ser fácil y se requiere muy poco esfuerzo cognitivo.

Palabras clave: metacomprensión, comprensión de lectura, precisión relativa, hipótesis del esfuerzo cognitivo. 


\section{Introduction}

Self-judgments of performance across many skills, tasks and domains are notoriously inaccurate (see Dunning, Johnson, Ehrlinger, \& Kruger, 2003). If more can be discerned about the factors that cause inaccurate performance judgments, then it is more likely that accuracy can be improved and self-corrective procedures implemented. The main benefit of improving accuracy is that overall performance quality may eventually be enhanced (see Dunning et al., 2003; Thiede, Anderson, \& Therriault, 2003). For example, advanced readers are often asked to read multiple texts in "paper and pencil" standardized testing situations (e.g., college entrance exams). If students can more accurately assess how their comprehension compares on one text versus another, then they can more efficiently distribute cognitive effort and resources to texts that are the least well understood if allowed a second chance to study or re-read the texts. We argue that approaches to improving accuracy would benefit from first having a deeper understanding of what causes inaccurate judgments of performance when texts are first encountered and readers make initial estimates of comprehension. Thus, the purpose of this investigation is to further examine the underlying cognitive-psychological processes that cause inaccurate performance judgments in the context of an initial study attempt.

Correlations that reflect adult readers' estimations of performance in light of actual performance indicate a low level of accuracy and average +.27 across many separate studies (Maki, 1998). In terms of what kinds of information readers use to make estimates that may cause this level of inaccuracy, there is a fair amount of evidence that readers use text difficulty as a factor in their estimates of future performance (e.g., Dunlosky, Baker, Rawson, \& Hertzog, 2006; Maki \& Serra, 1992; Linderholm, Zhao, Therriault, \& Cordell-McNulty, 2008; Rawson \& Dunlosky, 2002). One method to study the effects of text difficulty on metacomprehension is to manipulate the level of coherence of the texts in the experiment and determine how readers' judgments coincide with text coherence (e.g., Dunlosky et al., 2006; Rawson \& Dunlosky, 2002). Specifically, Dunlosky et al. (2006) operationalized text coherence in terms of how easy the stories were to understand based on how salient causal relations were in the text. Texts that have more salient causal relations between events are typically easier to understand, process, and recall. Based on this operationalization of text difficulty, some studies have found that readers are more confident in their future performance when texts are structured more coherently. But these studies did not correlate confidence with actual 
performance so it is unknown how accurate readers' estimates were as a function of difficulty of the reading task. In two studies that did assess accuracy, participants' processing of texts were manipulated by either giving participants more or less difficult texts (Weaver \& Bryant, 1995), or deleting letters in texts to force readers to process texts more actively (Maki, Foley, Kajer, Thompson, \& Willert, 1990). Both studies showed that, in general, when readers engaged in more cognitive processing, as a function of text/task difficulty, they were more accurate at estimating future performance. The optimum-effort hypothesis (Weaver \& Bryant, 1995) was proposed to explain one set of these findings. One tenet of this hypothesis is that when readers are not challenged enough, they devote minimal cognitive resources to monitoring their comprehension and, as a result, metacomprehension estimates become inaccurate. Thus, the specific goal of this study is to further investigate the power of one of the principles proposed by the optimum-effort hypothesis to explain factors that affect metacomprehension accuracy.

Related to the effect of text difficulty on metacomprehension accuracy is the readers' perceived level of text or task difficulty. In an exploratory study, the order of the topics presented in a series of two texts influenced how confident readers were in future comprehension test performance (Experiment 3: Linderholm et al., 2008). Readers' estimates of future performance decreased when a less familiar topic, the migratory patterns of songbirds, was presented first in a series of two texts. In contrast, estimates were higher when a more familiar topic, the origins of the moon, was presented first in the series of two texts. This study suggests that perhaps the order of texts biases readers' perceptions of overall task difficulty and could potentially influence the degree of cognitive effort expended on the task. These are intriguing findings that suggest that given the same set of texts, the ordering of texts by difficulty may bias readers' estimates of performance. Thus, we sought to further examine the optimum-effort hypothesis (Weaver \& Bryant, 1995) by manipulating the order of text materials from easy-to-hard or from hard-to-easy to determine if initial perceptions of the difficulty of the reading task biased readers' in terms of their cognitive effort, which would, in turn, affect metacomprehension accuracy rates.

In this investigation, we employed the measure of relative accuracy to assess readers' ability to accurately assess reading comprehension test performance over a series of texts that were ordered in a potentially biasing manner. Relative accuracy refers to how well readers are able to discriminate texts that are easy for them to comprehend from those that are more diffi- 
cult for them to comprehend. Relative accuracy is calculated by correlating readers' estimates with their actual level of performance (e.g., Griffin, Jee, \& Whiley, 2009; Griffin, Wiley, \& Thiede, 2008). A positive, strong correlation indicates that readers' estimates appropriately mirror their performance. To explore how cognitive effort influences performance judgments in reading, we manipulated the order of text difficulty in a series of seven expository texts. Participants read texts in one text difficulty order condition (easy-to-hard or hard-to-easy) and made subsequent judgments about their understanding of the texts. We hypothesized that the initial difficulty level of the texts in the series would create a cognitive effort bias and influence relative metacomprehension accuracy.

To test the hypothesis that the ordering of texts in a series, based on degree of text difficulty, could affect relative metacomprehension accuracy we conducted two experiments. In Experiment 1, we explored whether ordering texts based on text difficulty (easy-to-hard; hard-to easy) would affect relative metacomprehension accuracy. We expected that the easyto-hard text order condition would result in a lower average level of relative accuracy compared to the hard-to-easy condition. This prediction is based upon the premise that participants focused on the easier initial texts would be lulled into not putting forth the typical amount of cognitive effort when reading and making performance judgments on subsequent texts. In other words, the biasing effect of text order should be more prevalent when cognitive effort is at a minimum. This notion is in line with research findings that readers are more accurate in their judgments when more cognitive effort is expended during reading (Maki et al., 1990; Weaver \& Bryant, 1995) and is also supported by research that is outside the domain of reading, demonstrating that individuals are likely to become more accurate in their judgments if more cognitive effort is applied (e.g., Epley \& Gilovich, 2005; 2006). As a result the easyto-hard condition in this investigation should yield lower accuracy rates compared to the hardto-easy condition because the initial information (easier texts) would potentially bias readers to put forth less cognitive effort.

\section{Objectives}

If text ordering does indeed bias relative accuracy measures, then methods that encourage readers to put more cognitive effort into a task should improve accuracy in the easyto-hard condition. To this end, we sought to manipulate the degree of cognitive effort that participants in Experiment 2 would expend in the process of making their performance judg- 
ments to further explore whether the cognitive effort explanation could be used to understand relative accuracy rates.

\section{Experiment 1}

\section{Method}

\section{Participants}

A total of 49 undergraduate students from a large southeastern university participated in the study for partial course credit. There were 43 females and 6 males in the sample. The average age of the participants was 21.12 years $(S D=3.92$, range of $18-45$ years of age). All participants were native English speakers. Participants were randomly assigned to one condition: easy-to-hard or hard-to-easy. There were 25 participants in the hard-to-easy condition and 24 participants in the easy-to-hard condition.

\section{Materials}

Two sets of reading packets, consisting of the same seven short expository texts adopted from Weaver and Bryant (1995) and Rawson, Dunlosky, \& Thiede (2000), were developed and used in the study. The only difference between the reading packets was the order in which the texts were presented. The texts were presented in terms of reading difficulty, which was measured using the Flesch-Kincaid Grade Levels Scale (See Table 1 for the Flesch-Kincaid value for each text).

Table 1. Flesch-Kincaid Values of Text Materials

$\underline{\text { Text Titles }} \quad \underline{\text { Flesch-Kincaid Values }}$

\begin{tabular}{ll}
\hline Literature in the Classroom & 10.9 \\
Guilt, Good and Bad & 11.5 \\
Majority and Minority & 12.6 \\
Obesity & 12.9 \\
Virginia Wolf & 13.8 \\
Intelligence and Measurement & 15.8 \\
Inventions, Inventors, and Industry & 17.5 \\
\hline
\end{tabular}


For each of the seven texts in the reading packet, there was a corresponding reading comprehension test, which was also adopted from Weaver and Bryant (1995) and Rawson et al. (2000). The order in which the comprehension test packets were presented corresponded to the text order to which the particular participant was randomly assigned. Each comprehension test consisted of six multiple-choice questions. These multiple-choice questions were either implicit thematic questions or questions that were explicitly contained in the texts (See the Appendix for the samples of expository texts and comprehension test questions).

\section{Procedure}

Participants were administered the experiment in small groups in a quiet setting. All participants were randomly assigned to read under one condition: easy-to-hard or hard-toeasy. After reading each text in the assigned reading packet, participants were asked to predict how many test questions they thought they could answer correctly for a given text, using the scale of 0-6. This metacomprehension question was written on a separate page that followed each text. When participants read the texts, they were allowed to take as much time as they needed to comprehend each text, however, participants were not allowed to go back to the text once they started to answer the metacomprehension question.

When participants finished reading all of the texts in a reading packet, they were given the corresponding comprehension test packet. Participants were not allowed to refer back to the texts to respond to the questions.

\section{Instruments}

In both Experiments 1 and 2, packets of materials were presented to research participants in the form of paper copies. Participants were given writing utensils to respond to items in the packets.

\section{Data analysis}

Relative metacomprehension accuracy was operationalized as the intra-individual Pearson correlation between estimates of future test performance and actual test performance, as is commonly done in studies of relative accuracy (e.g., Griffin et al., 2009; Griffin et al., 2008). Using similar procedures as other researchers studying the same phenomenon facilitates comparing results across studies. A Pearson correlation coefficient, ranging from -1 to +1 , describes the extent to which texts that receive higher judgments are associated with high- 
er performance. In other words, relative metacomprehension accuracy indicates the ability of the reader to distinguish their level of comprehension between texts in a series. Although we did not have hypotheses regarding readers' average estimates (predictions) of future test performance or readers' average comprehension test performance as a function of text order, the raw data are provided for interested readers (see Table 2).

Table 2. Means and Standard Deviations of Readers' Estimates of Test Scores, Actual Test Scores, and Relative Accuracy as a Function of Text Difficulty Order in Experiments 1 and 2

\section{Experiment 1}

Easy-to-Hard

Estimates $\quad .68(.14)$

Test Scores $\quad .55(.16)$

Relative Accuracy

\section{Experiment 2}

\section{Easy-to-Hard}

$.62(.15)$

.55 (.12)

$.21(.23)$

\section{Hard-to-Easy}

$.19(.21)$

\section{Results}

We analyzed the effects of Text Order (easy-to-hard or hard-to-easy) on relative metacomprehension accuracy using an analysis of variance (ANOVA). In all analyses, the significance criterion was set to an alpha level of .05.

The results showed a significant effect of Text Order on relative accuracy, $F(1,48)=$ $5.92, M S e=.17, p<.05$. Participants in the easy-to-hard text order condition were significantly less accurate at judging relative text comprehension $(M=-.08, S D=.37)$ than participants in the hard-to-easy text order condition $(M=.21, S D=.46)$. 


\section{Experiment 2}

\section{Introduction}

The results of Experiment 1 demonstrated that, as expected, the easy-to-hard condition yielded lower metacomprehension accuracy compared to the hard-to-easy condition. These results provide support for the theory that text order biases readers to engage more or less cognitive effort into reading and this, in turn, influences relative metacomprehension accuracy. The purpose of Experiment 2 is to further test the claim that the bias of text order on metacomprehension judgments is due to cognitive effort. The instructions given to research participants in Experiment 2 were designed to increase the amount of cognitive effort put into the research task.

To ensure that research participants were putting forth their maximal amount of cognitive effort, we thought of the variety of factors that motivate participants in our college student sample. Given the time management demands of attending college, we theorized that students would be motivated to expend cognitive effort when time was of the essence. Drawing from theories of motivation, some individuals may be motivated to avoid extra work (e.g., Dowson \& McInerney, 2001) and thus will put forth more cognitive effort to do so and to save time. To manipulate cognitive effort, we gave the participants in Experiment 2 an additional set of instructions for completing the same tasks performed in Experiment 1. In detail, we informed participants in the experimental session that if they did not achieve a certain degree of accuracy in their future test performance judgments that they would have to stay longer to repeat part of the experiment.

We hypothesized that if cognitive effort was expended in an attempt to save on time and avoid working longer then the biasing effect of the easy-to-hard text order condition would be neutralized. In other words, we expected the cognitive effort manipulation to eliminate the difference in relative accuracy between the easy-to-hard and the hard-to-easy text order conditions. 


\section{Method}

\section{Participants}

A total of 50 undergraduate students from a large southeastern university participated the study for partial course credit. There were 39 females and 11 males in the sample. The average age was 20.64 years $(S D=1.98$; range of $18-28$ years of age). All participants were native English speakers. Participants were randomly assigned to one condition: easy-to-hard or hard-to-easy, and there were 25 participants in each condition.

\section{Materials}

The text and test materials used in Experiment 2 were the same as in Experiment 1.

\section{Procedure}

Participants were administered the experimental tasks in small groups in a quiet setting. We administered the same procedure in Experiment 2 as in Experiment 1, with the added component of cognitive effort manipulation described in the below.

Cognitive effort manipulation. To increase participants' cognitive effort during the reading task, they were given specific instructions prior to completing their reading packet. In detail, participants were told that they must reach a specific criterion of accuracy on their test predictions to be released from the experimental task; if they did not meet the criterion, they would be asked to stay longer and repeat the task with a set of new materials. Participants were not actually asked to stay longer. We simply used this manipulation in the preexperimental instructions to learn whether cognitive effort increases the adjustment process on which readers' estimates are based (Epley \& Gilovich, 2005; 2006). The experiment concluded with a debriefing procedure in which participants were told the exact purpose of the study and the purpose of the cognitive effort manipulation.

\section{Data Analysis}

Relative metacomprehension accuracy was calculated using readers' estimates of test performance correlated with actual test performance scores (see Table 2 for means). 


\section{Results}

We conducted an ANOVA to investigate how Text Order (easy-to-hard or hard to easy) affected relative metacomprehension accuracy. The significance criterion was again set at an alpha level of .05 . The results showed that with the added cognitive effort manipulation, there was no effect of Text Order, $F<1$. This confirms the hypothesis that cognitive effort is a viable explanation for the results of Experiment 1.

\section{Discussion and conclusions}

The results of this investigation confirmed that minimal cognitive effort negatively influences relative metacomprehension accuracy (Maki et al., 19909; Weaver \& Bryant, 1995), which supports and expands on one tenet of the optimum-effort hypothesis. First, we obtained evidence that initial information about the reading task serves to bias readers' relative accuracy, specifically when the ordering of texts in a series goes from easy to hard (Experiment 1) and this is in line with prior research suggesting order effects in estimating reading comprehension (Linderholm et al., 2008). Second, the results support the proposal that inaccuracy is tied to the cognitive effort involved in the estimation process (Weaver \& Bryant, 1995; see also Epley \& Gilovich, 2006; Zhao \& Linderholm, 2008) because the low level of accuracy in the easy-to-hard condition of Experiment 1 was eliminated when research participants were motivated to put more cognitive effort into the task (Experiment 2). An element that would have strengthened these findings even more would be if Experiment 2 also included a control condition similar to Experiment 1. Future studies should seek to add such a condition to replicate original findings.

Taken as a whole, these findings expand the optimum-effort hypothesis, in that, even perceptions of the degree of cognitive effort required for a task can influence metacomprehension accuracy - even if the items are identical but just presented in an order based on degree of text difficulty. That is, when research participants perceived that the task at hand may be easy, based on the relative ease of processing initial texts in a series, it decreased their ability to accurately discriminate well-understood from less-understood texts.

In addition to contributing to a theoretical understanding of metacomprehension accuracy, these results have practical implications with regard to assessment. Computerized adaptive testing typically begins with easy to moderately difficult items (e.g., Merrell \& Tymms, 
2007), which could have a biasing effect on one's ability to monitor performance accurately. And evidence suggests that ultimately performance can even be affected by the ordering of assessment items (e.g., Brennan, 1992; Kingston \& Dorans, 1984; Leary \& Dorans, 1985; Ortner, 2008; Zwick, 1991). This issue of order effects has garnered discussion among test developers, as some topics (e.g., personality traits) seem particularly susceptible to order effects (e.g., Ortner, 2008). Most pertinent to the topic of this current investigation, order effects appear to be particularly salient for assessing reading comprehension skills (e.g., Brennan, 1992; Davey \& Kapinus, 1985; Leary \& Dorans, 1985) and text order is sometimes manipulated in reading intervention studies to gradually expose struggling readers to more difficult texts (e.g., Carr \& Thompson, 1996). It could be that readers' estimates of performance are biased when testing and/or interventions begin with easy texts. Thus, the effect of text order is an important factor that should be examined further and certainly should not be overlooked when assessing students' reading abilities.

To summarize, the results of this study demonstrate that the degree of cognitive effort plays an important role in relative metacomprehension accuracy. A particularly biasing situation is when easy materials are presented first in an order of tasks, giving the reader the perception that few cognitive resources are required to complete the task at hand - and this results in inaccurate monitoring of performance. This situation can be ameliorated when readers apply additional cognitive effort and may be a first step to increasing relative accuracy and, eventually, improving overall reading performance. 


\section{References}

Brennan, R. (1992). The context of context effects. Applied Measurement in Education, 5, 225-264.

Carr, S., \& Thompson, B. (1996). The effects of prior knowledge and schema activation strategies on the inferential reading comprehension of children with and without learning disabilities. Learning Disability Quarterly, 19, 48-61.

Davey, B., \& Kapinus, B. (1985). Prior knowledge and recall of unfamiliar information: Reader and text factors. Journal of Educational Research, 78, 147-151.

Dowson, M., \& McInerney, D. M. (2001). Psychological parameters of students'social and work avoidance goals: A qualitative investigation. Journal of Educational Psychology, 93, 35-42.

Dunlosky, J., Baker, J. M. C., Rawson, K. A., \& Hertzog, C. (2006). Does aging influence people's metacomprehension? Effects of processing ease on judgments of text learning. Psychology and Aging, 21, 390-400.

Dunning, D., Johnson, K., Ehrlinger, J., \& Kruger, J. (2003). Why people fail to recognize their own incompetence. Current Directions in Psychological Science, 12, 83-97.

Epley, N., \& Gilovich, T. (2005). When effortful thinking influences judgmental anchoring: Differential effects of forewarning and incentives on self-generated and externally provided anchors. Journal of Behavioral Decision Making, 18, 199-212.

Epley, N., \& Gilovich, T. (2006). The anchoring and adjustment heuristic: Why the adjustments are insufficient. Psychological Science, 17, 311-318.

Griffin, T.D., Jee, B.D., \& Wiley, J. (2009). The effects of domain knowledge on metacomprehension accuracy. Memory \& Cognition, 37, 1001-1013.

Griffin, T.D., Wiley, J., \& Thiede, K.W. (2008). Individual differences, rereading, and self explanation: Concurrent processing and cue validity as constraints on metacomprehen sion accuracy. Memory \& Cognition, 36 (1), 93-103. . 
Kingston, N., \& Dorans, N. (1984). Item location effects and their implications for IRT equating and adaptive testing. Applied Psychological Measurement, 8, 147-154.

Leary, L., \& Dorans, N. (1985). Implications for altering the context in which test items appear: A historical perspective on an immediate concern. Review of Educational Research, 55, 387-413.

Linderholm, T., Zhao, Q., Therriault, D. J., \& Cordell-McNulty, K. (2008). Metacomprehension estimates investigated within an anchoring and adjustment framework. Metacognition and Learning, 3, 175-188.

Maki, R. H., (1998). Test prediction over text materials. In D. J. Hacker, J. Dunlosky, \& A. C. Graesser (Eds.), Metacognition in educational theory and practice (pp.117-144). Hillsdale, NJ: Erlbaum.

Maki, R. H., \& Serra, M. (1992). The basis of text predictions for text material. Journal of Experimental Psychology: Learning, Memory, \& Cognition, 18,116-126.

Maki, R. H., Foley, J. M., Kajer, W. K., Thompson, R. C., \& Willert, M. G. (1990). Increased processing enhances calibration of comprehension. Journal of Experimental Psychology: Learning, Memory, \& Cognition, 16, 609-616.

Merrell, C., \& Tymms, P. (2007). Identifying reading problems with computer-adaptive assessments. Journal of Computer Assisted Learning, 23, 27-35.

Ortner, T. (2008). Effects of changed item order: A cautionary note to practitioners jumping to computerized adaptive testing for personality assessment. International Journal of Selection and Assessment, 16, 249-257.

Rawson, K. A., \& Dunlosky, J. (2002). Are performance predictions for text based on ease of processing? Journal of Experimental Psychology: Learning, Memory, \& Cognition, $28,69-80$.

Rawson, K. A., Dunlosky, J., \& Thiede, K. W., (2000). The rereading effect: Metacomprehension accuracy improves across reading trials. Memory \& Cognition, 28, 10041010.

Thiede, K.W., Anderson, M.C.M., \& Therriault, D., (2003). Accuracy of metacognitive monitoring affects learning of texts. Journal of Educational Psychology, 95, 66-73. 
Weaver, C. A., III, \& Bryant, D. S. (1995). Monitoring of comprehension: The role of text difficulty in metamemory for narrative and expository text. Memory \& Cognition, 23, $12-22$.

Zhao, Q., \& Linderholm, T. (2008). Adult Metacomprehension: Judgment processes and accuracy constraints. Educational Psychology Review, 20(2), 191-206.

Zwick, R. (1991). Effects of item order and context on estimation of NAEP reading proficiency. Educational Measurement: Issues and Practice, 10, 10-16. 


\section{Appendix}

\section{Sample Text}

Intelligence and Measurement

In 1921, leading investigators in the field of intelligence participated in a symposium, "Intelligence and Its Measurement," sponsored by the Journal of Educational Psychology. They defined the title concept, producing almost as many definitions as there were definers, but reached no consensus. One contemporary observer was prompted to quip that intelligence seemed merely to be the capacity to do well on an intelligence test. Now, sixty years later, the situation seems little changed. As Yale's Robert J. Sternberg, an influential cognitive psychologist warns, "If we are to seek genuine understanding of the relationship between natural intelligence and measured intelligence (IQ), there is one route that clearly will not lead us to the heart of the problem and that we must avoid at all costs. This route is defining away (rather than defining) intelligence as whatever it is that the IQ tests measure."

The dominant approach followed by researchers attempting to define intelligence has been factor analysis, a statistical method that examines mental ability test scores with an eye to discerning constellations of test scores that are closely related to each other. The underlying thesis is that where a correlation appears among the scores of many people on tests of different mental abilities, a single factor of intelligence must be common to performance on those tests. Charles Spearman, originator of factor analysis, held that two kinds of factors form the basis of intelligence: a general factor and specific factors. Subsequent theorists divided the general factor into two or more sub factors, the two most generally agreed upon being verbal-educational and practical-mechanical abilities. Factor analysis has listed many discrete mental abilities and produced models that show how they combine, but it has not suggested how these abilities work. It has also not been productive in dealing with adaptational ability or practical problem solving.

A more recent approach is process analysis, whose thrust is to analyze the processes of test performance rather than the products of test performance. Process analysts, says Dr. Sternberg, do not reject the findings of factor analysis. Rather, they seek "to supplement our understanding of the factors of intelligence with an understanding of the processes that are responsible at least in part for the generation of these factors as sources of individual difference." The counterpart of the factor as a unit of analysis is the component, described by Dr. Sternberg as "an elementary information process that operates upon internal representations of objects or symbols.” Componential studies have been subjected to statistical analysis, and the findings have clarified how certain tasks are performed. 
However, like factor analysis, process analysis has so far provided few insights into practical problem solving and adaptation to real-world environments.

Dr. Sternberg hopes that the application of componential analysis to simulations of real-world task performance will contribute to an understanding of how intelligence operates in that area of human activity. Some in the field say that identifying factors and processes is worthwhile, but that doing so will not lead to a definition of intelligence. These critics warn that the models produced by such research may become the basis for some future statement that intelligence is what the models model.

\section{Sample Test Questions}

\section{Sample Implicit Question}

1. The author's primary purpose in the passage is to

a. suggest that despite some progress having been made, the true nature of intelligence is not yet understood

b. prove that factor analysis provides a definitive explanation of the various skills which make up intelligence

c. contrast the techniques of factor analysis with those used in process analysis

d. argue that intelligence will probably never be adequately defined

e. explain the most recent developments in the field of cognitive theory

\section{Sample Explicit Question}

2. The passage discusses the general factor of intelligence being divided into sub factors by some factor analysts. Which of the following is one of the sub factors mentioned?
a. verbal-educational
b. practical-educational
c. verbal-reasoning
d. practical-reasoning
e. mechanical-educational 